\title{
Time Course of Closure of the Ductus Venosus in the Newborn Lamb
}

\author{
JOE ZINK AND GARRY R. VAN PETTEN \\ Division of Pharmacology and Therapeutics, Faculty of Medicine, University of Calgary, Calgary, Alberta T2N IN4, \\ Canada
}

\section{Summary}

The present study was designed to obtain quantitative data on the extent of portocaval shunting and the time course of closure of the ductus venosus in newborn lambs. Experiments were conducted on eight newborn lambs prepared with chronic portal catheters. The time course of the postnatal closure of the ductus venosus was determined by following the distribution of radiolabelled microspheres injected into the lamb's portal vein $24,48,96$, and $168 \mathrm{hr}$ after birth. The fraction of the portal blood flow which bypassed the liver was highly variable. In some animals, the ductus venosus was almost completely closed when the first microspheres were injected $24 \mathrm{hr}$ after birth. In others, almost $40 \%$ of the portal blood flow bypassed the hepatic circulation at this time. On average, only $77 \%$ of the portal blood flow was directed to the liver in the 1-day lambs. In most cases, closure had occurred by $48 \mathrm{hr}$ after birth, but some animals continued to divert a significant fraction of the portal flow away from the hepatic circulation.

\section{Speculation}

At birth, the umbilical perfusion of the liver ceases and the hepatic circulation shifts to a much greater reliance on its portal blood flow. Patency of the ductus venosus during the 1st wk after birth may divert a sizeable fraction of the portal blood flow away from the liver and reduce the hepatic blood flow to levels which limit oxygen exchange and the development of metabolic functions in the postnatal period.

The liver blood supply is greatly affected by the collapse of the placental circulation at birth. In utero, umbilical venous blood provides the liver with $80 \%$ of its blood flow (17) and almost all of its oxygen supply (5). The portal venous blood is poorly oxygenated and distributed primarily to the right side of the organ $(5,14)$. Because there is a negligible flow through the hepatic artery $(10,17)$, the loss of the hepatic umbilical flow at birth removes the main source of oxygen and begins a difficult period of transition as the liver circulation shifts to a much greater reliance on its portal inflow.

Measurements of portal blood flow obtained in the immediate postnatal period indicate that it is not much greater than the equivalent flow in the fetus (2). However, it must now perfuse a mass of tissue five times greater than the prenatal distribution (17). During this time continued patency of the ductus venosus may further compromise the hepatic circulation by operating as a portocaval shunt. In human infants, as well as sheep and dogs, it is known that this vessel remains partly open after birth $(11,14)$ but the time course of its closure and the fraction of the portal flow it diverts are unknown. The present study was designed to obtain quantitative data on the extent of portocaval shunting and the time course of closure of the ductus venosus in newborn lambs.

\section{MATERIALS AND METHODS}

Experiments were conducted on eight newborn lambs prepared with chronic portal catheters. The lambs were delivered at gesta- tional ages that ranged from 144-148 days and none experienced complications during labor. All lambs were healthy, energetic, and nursing freely from the ewe.

The portal vein catheter was implanted 6-12 hr after birth. Lambs were anesthetized with 1-2\% halothane in $100 \%$ oxygen and the abdomen was opened with a $2 \mathrm{~cm}$ laparotomy. Using asceptic procedures, a short segment of intestine was withdrawn and a small tributary of the mesenteric vein was exposed. From this site, a silicon rubber catheter (O.D. 0.047 in.) was threaded 10 $\mathrm{cm}$ into the portal vein and secured. The abdominal contents were replaced and $0.5 \mathrm{cc}$ of penicillin (100,000 units) dihydrostreptomycin $(0.12 \mathrm{~g})$ was added to the peritoneal cavity before closure. The catheter was then tunnelled subcutaneously to a canvas pack on the lamb's flank. The entire procedure lasted $30-45$ min and was very well tolerated. The lambs were ambulatory and nursing a few min after their return to the ewe.

The time course of the postnatal closure of the ductus venosus was determined by following the distribution of radiolabeled microspheres injected into the lamb's portal vein $24,48,96$, and $168 \mathrm{hr}$ after birth. The spheres were nominally $15 \mu$ in size, suspended in $20 \%$ Dextran and labeled with either $\mathrm{Ce}, \mathrm{Cr}, \mathrm{Sc}$, or Gd (New England Nuclear). On the occasion of each injection, the lamb was unrestrained but confined while the catheter was flushed with saline. The spheres were injected in a $0.5 \mathrm{cc}$ volume and flushed with $2.5 \mathrm{cc}$ of saline. Data obtained from other lambs prepared with two portal catheters have shown that the portal pressure is unaffected by this injection procedure.

The animals were killed with pentobarbital after the fourth injection. At autopsy, the liver and lungs were removed while the remainder of the carcass was placed in an aluminum pan to be dried for 2 days at $200^{\circ} \mathrm{C}$. The radioactive content of the liver and lungs was determined by homogenizing the entire organs and counting aliquots equivalent to about $10 \%$ of the organ weights. The dried carcass was ashed at $330^{\circ} \mathrm{C}$ for $4 \mathrm{hr}$ and its radioactive content was obtained by counting aliquots of the mixed ashes.

The tissues were analyzed for gamma radioactivity with a Searle spectrometer and the activity attributable to the separate isotopes was derived by simultaneous stripping on a PDP $11 / 40$ computer. Data analysis was accomplished by complete block analysis of variance with tests of multiple comparison by least squared differences. The data were shown to be suitable for analysis of variance by tests of additivity, normality, independence of errors, and variance homogeneity $(15,16)$.

\section{RESULTS}

The fraction of the portal blood flow which bypassed the liver was highly variable in the eight newborn lambs. In some animals, the ductus venosus was almost completely closed when the first microspheres were injected $24 \mathrm{hr}$ after birth (L5, L8; Table 1). In others, almost $40 \%$ of the portal blood flow bypassed the hepatic circulation at this time (L3, L4, L7; Table 1). On average, only $77 \%$ of the portal blood flow was directed to the liver in the 1 day-old lambs.

On subsequent days, the flow that was shunted through the ductus venosus progressively decreased (Fig. 1). In most lambs, 
Table 1. Fraction of portal blood flow delivered to the liver of the newborn lamb ${ }^{1}$

\begin{tabular}{ccccc}
\hline Experiment & Day 1 & Day 2 & Day 4 & Day 7 \\
\hline L1 & 70 & 82 & 96 & 98 \\
L2 & 82 & 79 & 95 & 88 \\
L3 & 63 & 58 & 46 & 71 \\
L4 & 63 & 95 & 96 & 99 \\
L5 & 94 & 95 & 97 & 89 \\
L6 & 84 & 96 & 98 & 94 \\
L7 & 66 & 76 & 95 & 95 \\
L8 & 91 & 98 & 99 & 97
\end{tabular}

$\begin{array}{lcccc}\text { Mean } \pm \text { SE } & 77 \% * * \pm 3 & 85 \% \pm 3 & 90 \% \pm 3 & 91 \% \pm 3 \\ \begin{array}{c}\text { Heart rate } \\ \pm \text { SE }\end{array} & 150 \pm 7 & 154 \pm 6 & 160 \pm 5 & 159 \pm 6 \\ \begin{array}{c}\text { Respiratory } \\ \text { rate } \pm \text { SE }\end{array} & 72 \pm 16 & 86 \pm 11 & 83 \pm 11 & 74 \pm 13 \\ & & & & \end{array}$

${ }^{1}$ Fraction of portal blood flow delivered to the liver of the newborn lamb. SE: standard error of the mean. ${ }^{* *}: P<0.01$ relative to day 7 .

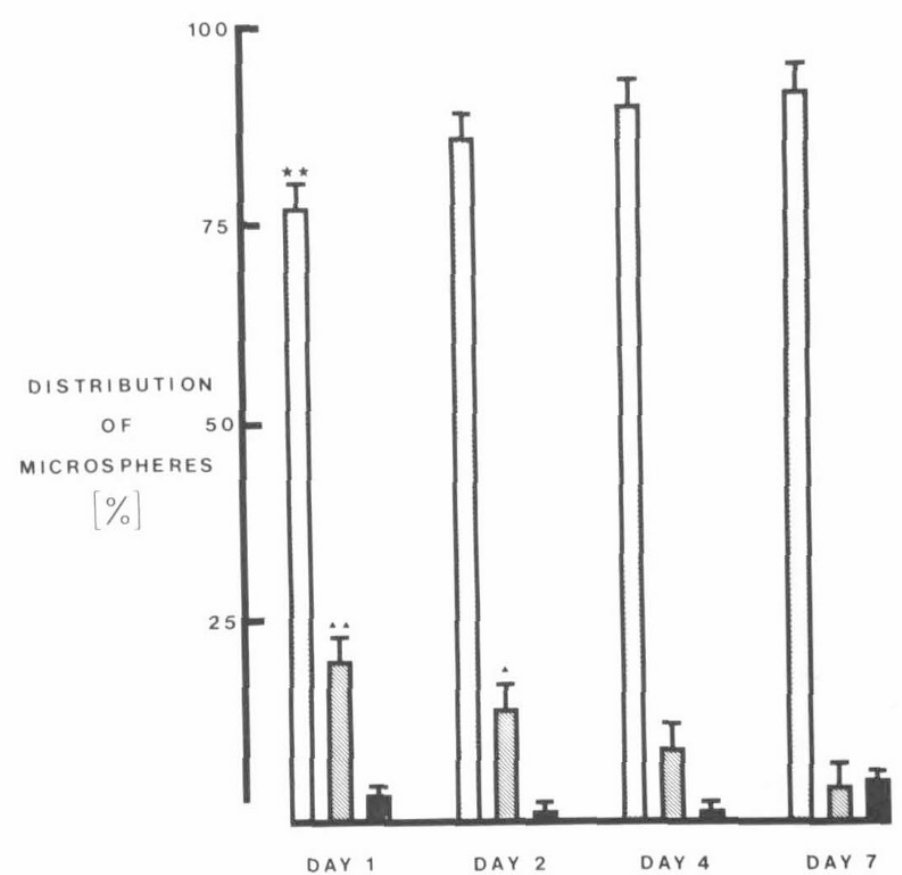

Fig. 1. The distribution of portal blood flow as measured in newborn lambs in the 1st wk after birth. For each day, the first column indicates the fraction delivered to the liver, the second and third columns indicate the fractions recovered from the lungs and carcass, respectively. Statistical comparisons to day $7:{ }^{* *}, \boldsymbol{\Delta} \mathbf{\Delta} P<0.01 ; \boldsymbol{\Delta} P<0.05$.

closure had occurred by $48 \mathrm{hr}$ after birth, but some animals continued to divert a significant fraction of the portal flow away from the hepatic circulation. The ductus venosus of one lamb remained patent even until the 7 th day after birth when it shunted $30 \%$ of the portal flow away from the liver (L3: Table 1). Heart rates and respiratory rates were recorded before each injection and showed no changes during the 1st wk. Neither parameter was significantly correlated to the shunting of the ductus venosus.

\section{DISCUSSION}

Using radiographic techniques Peltonen and Hivonen $(13,14)$ have observed that the ductus venosus of newborn lambs and human infants can be visualized for about 3-4 days after birth. In some cases, contrast media can be shown to flow through the shunt as late as 12 days. Similar data have been reported for newborn dogs although in this species patency was not observed beyond 3 days after birth (11). Taken together, these radiographic studies provide some indication of the time course of closure, but they have not supplied serial measurements of the shunt flow. Perhaps of more importance is the problem of the injection pressure that is required to fill the low-flow portal vasculature with contrast medium. The elevation of portal pressure caused by this procedure passively distends the duct, thus increasing flow and improving its radiographic visualization (1).

The data obtained in the present study were acquired without any interference with the normal postnatal portal pressure and provide the first quantitative measurements of portocaval shunting in the neonate. These data indicate that only $75 \%$ of the portal blood flow actually perfuses the liver in the period immediately after birth. This fraction is less than that reported for the fetus wherein $90-95 \%$ of the portal flow enters the hepatic circulation (5). Because portocaval shunting through the ductus venosus can be as much as $54 \%, 4$ days after birth, it is apparent that the patency of this shunt could be a major determinant of the postnatal liver blood flow.

Although there is some indication that flow through the ductus venosus may persist even beyond the 1st wk (Table 1), for the most part, closure occurs by the 2 nd or 4 th day after birth. The physiologic processes that contribute to the reduction of shunt flow are unknown at the present time, but Meyer and Lind (12) have suggested that a decreased pressure in the portal sinus leads to a passive collapse of the vessel. This distending pressure has not been measured directly but the portal pressure of the sheep fetus has been reported (5), and it is not substantially different from the pressures that were recorded in the present study with 1to 2-day-old lambs (about $6 \mathrm{~mm} \mathrm{Hg}$ ). Portal sinus pressure may be closer to the pressure in the umbilical vein, but Edelstone et al. (5) have noted that there is only a $1 \mathrm{~mm} \mathrm{Hg}$ pressure gradient between the umbilical and portal veins in the sheep fetus. Because the ductus venosus is innervated $(9,14)$ and responsive to endogenous vasoactive substances (6), it is possible that its closure is an active process mediated by neural or blood-borne vasoconstrictors.

Congenital patency of the ductus venosus, which does not resolve with time, is associated with all the usual signs of hepatic insufficiency $(4,8)$. However, in the present study, one lamb continued to shunt a sizeable fraction of the portal flow through the ductus venosus on the 7 th day, with no evidence of hepatic dysfunction or impairment of health. Thus, it is possible that the liver is more sensitive to a reduction of blood flow after the immediate postnatal period. Similarily, in the presence of neonatal jaundice or hepatitis, patency of the ductus venosus may be more serious and reduce hepatic blood flow to levels which limit the exchange of oxygen and metabolic products.

Inadequacy of the postnatal liver perfusion is suggested by degenerative changes that have been observed in the livers of infants that die in the first few wk after birth. In such cases, Emery (7) has reported that parenchymal cell degeneration, shrinkage and sinusoidal dilatation are more frequent on the left side of the organ. This supports a vascular etiology because it is this side of the liver which is most affected by the reduction of blood flow after birth. Patency of the ductus venosus, which is frequently observed in such cases (3), would divert portal blood flow to the inferior vena cava rather than the left side of the liver. Thus, the left side could be hypoperfused in the postnatal period even though it received more flow than the right side in utero (17).

The results of the present study indicate that flow through the ductus venosus ceases during the first wk after birth. However, it is important to distinguish this "apparent" closure from "organic" closure. From autopsies conducted on infants who died when they were 2-3 wk of age, Blanc (3) has observed that in $50 \%$ of the cases the ductus venosus was not organically sealed. Thus, it would seem that there remains a potential for shunt flow to resume. In studies of newborn lambs and human infants, Peltonen and Hirvonen $(13,14)$ have shown that infusions of drugs such as norepinephrine, acetylcholine, or serotonin can cause contrast material to flow through the ductus venosus even after its closure 
had been documented by radiographic criteria. The vessel has also been reported to dilate in response to asphyxia or vagal stimulation in newborn lambs (14). Considering these reports, the closure that was observed in the present study should be considered physiologic and not to imply that the shunt flow could not resume under different circumstances.

\section{CONCLUSION}

The extent of portocaval shunting through the ductus venosus and the time course of its closure were examined in eight newborn lambs. Twenty-four hr after birth, the fraction of the portal blood flow which bypassed the liver was highly variable. In some animals, the duct was almost completely closed and remained so for the duration of the week. In others, almost $40 \%$ of the portal flow was diverted away from the hepatic circulation. Portal hepatic perfusion averaged only $77 \%$ in the 1-day-old lambs. In most cases, closure occurred by $48 \mathrm{hr}$ after birth, but some lambs continued to shunt a significant fraction directly to the inferior vena cava even on the 7 th day after birth.

\section{REFERENCES AND NOTES}

1. Barclay, A. E., Franklin, K. J., and Prichard, M. M. L.: The mechanism of closure of the ductus venosus. Brit. J. Radiol. 15: 66 (1942).

2. Behrman, R. E., and Lees, M. H.: Organ blood flows of the fetal, newborn and adult rhesus monkey. Biol. Neonate, 18: 330 (1971).

3. Blanc, W. B.: Premature closure of the ductus venosus. Amer. J. Dis. Child, 100; $572(1960)$

4. Cornelius, L. M., Thrall, D. E., Halliwell, W. H., Frank, G. M., Kern, A. J., and Woods, C. B.: Anomalous portosystemic anastomoses associated with chronic hepatic insufficiency in six young dogs. J.A.V.M.A., 167: 220 (1975).

5. Edelstone, D. I., Rudolph, A. M., and Heymann, M. A.: Liver and ductus venosus blood flows in fetal lambs in utero. Circ. Res., 42: 426 (1978).

6. Ehinger, B., Gennser, G., Owman, C., Persson, H., and Sjoberg, N. O.: Histo- chemical and pharmacological studies on amine mechanisms in the umbilical cord, umbilical vein and ductus venosus of the human fetus. Acta Physiol. Scand., 72: 15 (1968).

7. Emery, J. L.: Degenerative changes in the left lobe of the liver in the newborn. Arch. Dis. Child., 27: 558 (1952).

8. Ewing, G. O., Suter, P. F., and Bailey, C. S.: Hepatic insufficiency associated with congenital anomalies of the portal vein in dogs. Am. Anim. Hosp. Ass. J., 10: 463 (1974).

9. Gennser, G., Owman, C., and Sjoberg, N. O.: Histochemical evidence of an aminergic sphincter mechanism in the ductus venosus of the human foetus. In: J. Horsky and Z. K. Stembera: Intrauterine dangers to the fetus, p. 180 (Exerpta Med. Fdn., Prague, 1967).

10. Lind, J.: Changes in the liver circulation at birth. Ann. N.Y. Acad. Sci., 111: 110 (1963).

11. Lohse, C. L., and Suter, P. F.: Functional closure of the ductus venosus during early postnatal life in the dog. Amer. J. Vet. Res., $38: 839$ (1977).

12. Meyer, W. W., and Lind, J.: The ductus venosus and the mechanism of its closure. Arch. Dis. Child., 41: 597 (1966).

13. Peltonen, T., and Hirvonen, L.: The ductus venosus. Acta Ped., 52: 202 (1963).

14. Peltonen, T., and Hirvonen, L.: Experimental studies on fetal and neonatal circulation. Acta Ped. Suppl., 161: 2 (1965).

15. Snedecor, G. W., and Cochran, W. G.: Statistical methods, p. 321. (Iowa State University Press, Sixth Ed., Ames, Iowa, 1967).

16. Sokal, R. R., and Rohlf, F. J.: Assumptions of Analysis of Variance. In: Biometry. The principles and practice of statistics in biological research. (W. H. Freeman and Co., San Francisco, 1969).

17. Zink, J., and Van Petten, G. R. The effect of norepinephrine on blood flor through the fetal liver and ductus venosus. Amer. J. Obs. Gynecol. in press (1979).

18. The authors thank Mr. Peter van Muyden for his excellent technical assistance.

19. This research was supported by the Medical Research Council of Canada and the Canadian Heart Foundation.

20. This research was presented in a preliminary form to the April 1978 meeting of FASEB.

21. Requests for reprints should be addressed to: Joe Zink, Department of Pharmacology, Faculty of Medicine, Dalhousie University, Halifax, Nova Scotia, B3H $4 \mathrm{H} 7$.

22. Received for publication June 2, 1978.

23. Accepted for publication January 23, 1979. 